\title{
UPON TYPE, FREQUENCY AND SOME CLINICAL ASPECTS OF PSYCHOTIC SYMPTOMS IN ALZHEIMER'S DISEASE
}

\author{
Mariana Arnaoudova \\ Third Psychiatric Clinic MHAT "St. Marina" - Varna \\ Department of Psychiatry, Medical University, Varna, Bulgaria
}

\section{SUMMARY:}

Various psychotic disorders develop often at different stages of the disease. A comprehensive approach of type, frequency and clinical aspects of the psychotic disorders patients with Alzheimer's disease (AD) can optimize management of these conditions in patients with dementia. We examined 120 patients with probable AD. The routine clinical examination and observation were used to delineate the most common psychotic symptoms. Delusions, found in the explored patients were predominantly paranoid. The delusions are often short lived and lack complexity of that seen in schizophrenia. In number of cases they are difficult to be distinguished from confabulations. Hallucinations were mostly verbal, visual and tactile. Misidentification syndromes were identified in a considerable number of patients. They are often disputable or have been classified as delusions or hallucinations, depending on interpretation of psychotic phenomena. We discuss different forms of misidentification. The presence of psychotic symptoms predicts the occurrence and frequency of different forms of aggression and destructive behavior. BPSD

Key words: Alzheimer's disease, psychotic symptoms,

\section{INTRODUCTION:}

Various psychotic disorders develop often at different stages of Alzheimer's disease (AD). Behavioral and Psychological Symptoms of Dementia (BPSD) are an integral part of the disease process. In Alzheimer's classic case description (1906) psychotic symptoms were among the prominent manifestations of the disease (2). It has been disputable about prevalence of different BPSD in demented patients $(1,16,19)$. The rates of all the psychotic symptoms vary widely depending on how the phenomena are defined, patients' sample, stage of the disease, accurate data, investigator's skills, etc. A psychosis of Alzheimer's disease has been accepted since the 1999 conference of the International Psychogeriatric Association (IPA). Psychotic symptoms are among the most intrusive and difficult BPSD to cope with. Estimates of their frequency differ in a broad range $(17,20)$. A comprehensive approach of type, frequency and clinical aspects of the psychotic disorders in $\mathrm{AD}$ patients can optimize management of these conditions in patients with dementia.

\section{AIM:}

The aim of our study was to explore the type, frequency and clinical aspects of the psychotic disorders in $\mathrm{AD}$ patients.

\section{SUBJECTS AND METHODS:}

We examined 120 patients, admitted at the gerontopsychiatry department of Third psychiatric clinic at MHAT "St.Marina"-Varna. Patients were diagnosed according to the criteria of ICD-10, DSM-IV and NINCDS/ ADRD criteria for probable AD. The routine clinical examination and observation were used to delineate the most common psychotic symptoms. The comprehensive clinical assessment included a longitudinal review of the current symptoms, psychiatric, medical and drug history, family history, observation of the psychotic phenomena in the course of the interview and during the stay at the department. An important information was taken from a reliable caregiver for a more precise and adequate assessment of cognitively impaired patients.

\section{RESULTS:}

We found out multiple coexsisting BPSD in the explored AD patients. This is in contrast with the relatively monosymptomatic clinical presentation of the classic psychiatric disorders. Psychosis in AD is represented by the occurrence of delusions and hallucinations that had their onset after the appearance of the dementia syndrome, a duration at least for a month, severe enough to impair patient's functioning, when other somatic, organic or psychotic disorders are excluded (17). According to Mendez et al. (1990), Cooper et al. (1991), Ballard et al. (1995), Gormly, Rizwan (1998), coexistence of delusions and hallucinations is in $40-65 \%$ of cases; delusions in- $30-50 \%$; hallucinations$10-20 \%(21,8,3,13)$. The prevalence of delusions varies between $10 \%$ to about $73 \%$ depending on the study population $(22,25)$. 
Delusions, found in our study were predominantly paranoid: delusions of harm in $44(36.6 \%)$ patients, delusions of theft in 41 (34.16\%); delusions of reference in 22 (18.33\%); hypochondriacal delusions in $15(12.5 \%)$; delusions of poisoning in $15(12.55 \%)$, delusions of infidelity in $7(5.83 \%)$ patients and persecutory delusions in 8 (6.66\%). (Fig.1).

Fig.1. Paranoid delusions

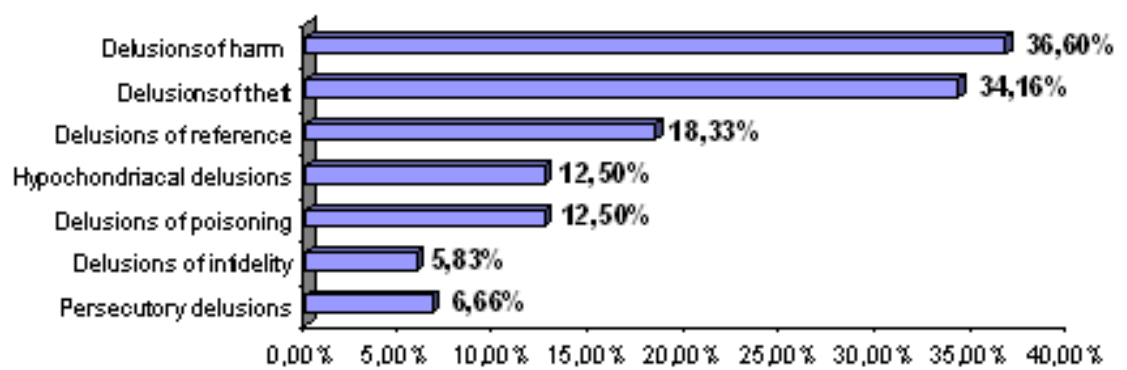

Regarding hallucinations, verbal were found in $13.33 \%$; visual in $12.5 \%$ and tactile (mostly genital)- in $10 \%$ in clinical settings that have found prevalence rates for all of the patients. Our results are in consistency with studies hallucinations of $10 \%(4,12,20)$. (Fig. 2$)$.

Fig. 2. Hallucinations

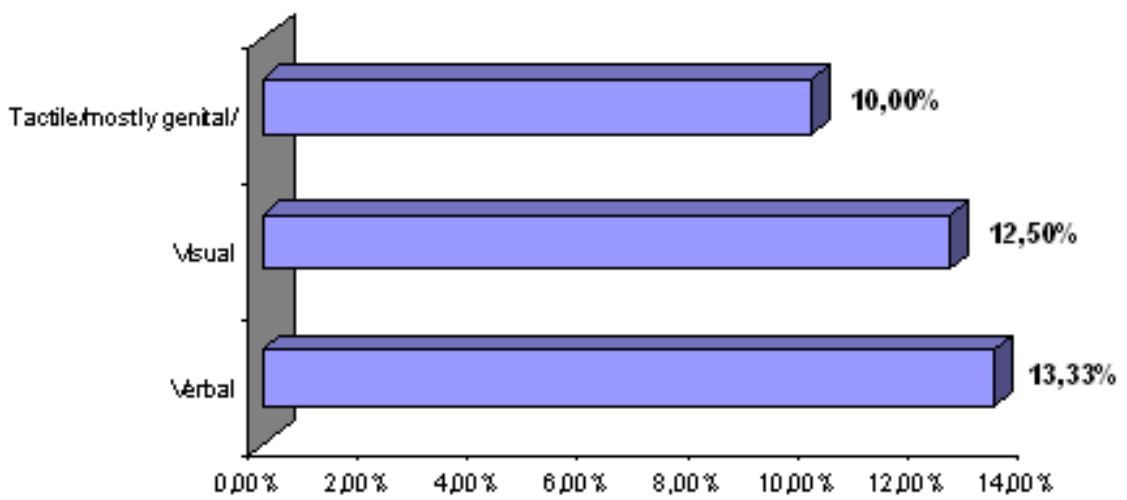

Misidentitication syndromes were identitied in 23 patients. Capgras syndrome (the misidentified person is accepted as looking exactly the same as their "double"), often called the syndrome of imposters (10) was present in $6(5 \%)$ of all demented patients. Other presentation of misidentifications found: presence of persons in the

Fig. 3. Misidentification syndromes

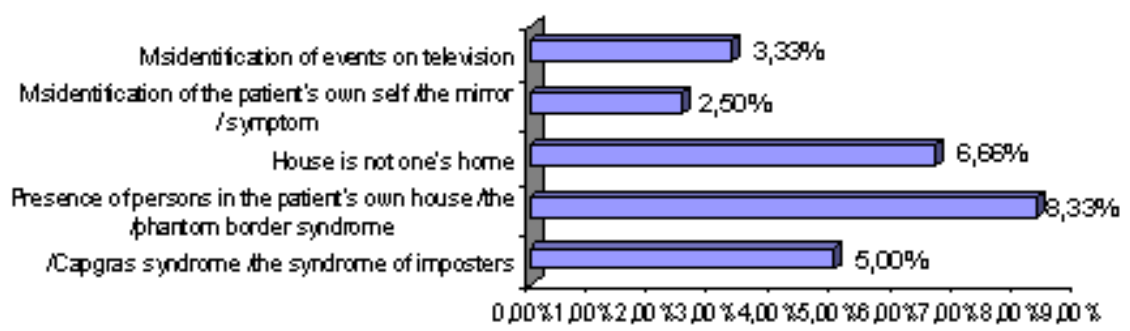




\section{DISCUSSION}

Delusions are false beliefs about external reality that are firmly held despite evidence. In endogeneous psychotic disorders such as schizophrenia, delusions are commonly accompanied by evidence of a thought disorder, neologisms and typical emotional disturbances. It is interesting that some authors classify BPSD in dementia as positive and negative symptoms, psychosis being among positive $(7,23)$. It is near the similar classification in schizophrenia where delusions and hallucinations are included in the positive register. The difference of psychotic symptoms in dementia is they, except the above mentioned characteristics, tend to lack the complexity and systematization of the delusions seen in schizophrenia. They are most probably connected with memory impairment in contrast with schizophrenic patients with similar delusions. Grandiose or bizarre delusions observed in patients with schizophrenia or mood disorders are unusual in demented patients. Cognitive impairment provokes most of the paranoid delusions. It is most obvious with the delusions of robbery. Due to their short life they may not be present at every examination. It is known, that BPSD emerge at any time in the course of the disease and fluctuate $(9,18)$. Other authors connect their short duration with difficulties to distinguish them from confabulations (15). Our patients were evaluated at their first hospitalization due to psychotic symptoms or behavioral problems. Wandering or agitation are the behavioral symptoms most often associated with the delusions of theft, harm, persecution, the family members or caregivers mostly suffering.
Concerning hallucinations, one has to have in mind, that visual are highly correlated with visual pathology (14) and verbal- with hard of hearing.

Misidentifications are often disputable or have been classified as delusions (delusional misidentification) or hallucinations, depending on interpretation of psychotic phenomena. Some authors find occurring in about 23-30\% of sufferers at some time and about $19 \%$ during a single year $(6,24)$. Misidentifications in dementia are examples of disorders of perception (5). Unlike hallucinations, misidentifications are misperceptions of external stimuli and can be defined as misperceptions with an associated belief that is held with delusional intensity. Ellis et al. (1997) proposed that Capgras patients interpret the loss of affective response for familiar people in a paranoid suspicious way (11). In some instances anger or violence can be provoked towards perceived impostor. We should underline the difficulty to precise eliciting the phenomena in such patients as many factors have an influence- degree of dementia, collaboration of patients, adequate informants' data etc.

\section{CONCLUSION}

Alzheimer's disease is accompanied by a variety of psychotic symptoms. The key of accurate diagnosis of psychotic disorders lies in a careful and profound assessment of the patients, including informant input. Psychotic phenomena predict the occurrence and frequency of different forms of aggression and destructive behavior and present a great burden for the families and caregivers. The purpose of their more careful and profound research is to find adequate and optimal management..

\section{REFERENCES:}

1. Landes AM, Sperry SD, Strauss ME. Prevalence of Apathy, Dysphoria, and Depression in Relation to Dementia Severity in Alzheimer's disease. J Neuropsychiatry Clin Neurosci 2005 Summer; 17(3): 342-349. CrossRef] [PubMed]

2. Alzheimer A. Uber einen eigenartigen schweren Er Krankungsprozeb der Hirnrinde. Neurologisches Centralblatt 1906; 23:1129-1136.

3. Ballard C, Saad K, Patel A, Gahir M, Solis M, Coope B, Wilcock G. The prevalence and phenomenology of psychotic symptoms in dementia sufferes. Int J Geriatr Psychiatry 1995; 10:477-85.

4. Ballard C, Walker M. Neuropsychiatric aspects of Alzheimer's disease. Cur Psychiatry Rep 1999 Oct; 1(1):49-60. [PubMed]

5. Burns A. Misidentifications. Int
Psychogeriatr 1996; 8 (Supp13):393-397. [PubMed]

6. Burns A, Jacoby R, Levy R. Psychiatric phenomena in Alzheimer's disease. II. Disorders of perception.. Br J Psychiatry 1990 Jul;157:76-81, 92-94. [PubMed]

7. Cadieux NL, Greve KW. Emotion processing in Alzheimer's disease. J Int Neuropsychol Soc 19971997 Sep;3(5):41119. [PubMed]

8. Cooper JK, Mungas D, Verma M, Weiler P. Psychotic symptoms in Alzheimer's disease. Int $J$ Geriatr Psychiatry 1991; 6:721-6.

9. Devanand DP, Jacobs DM, Tang M, Del Castillo-Castaneda C, Sano M. Marder K. et al. The course of psychopathologic features in mild to moderate Alzheimer's disease. Arch Gen Psychiatry 1997 Mar;54(3):257-63.

\section{[PubMed]}

10. Ellis HD, Young AW. Accounting for delusional misidentifications. $\mathrm{Br} \mathrm{J}$ Psychiatr 1990 Aug; 157:239-248. [PubMed]

11. Ellis HD, Young AW, Quayle AH, de Pauw KW. Reduced autonomic responses to faces in Capgras delusion. Proceedings of the Royal Society. Proc Biol Sci. 1997 Jul 22; 264(1384:1085-1092. [PubMed]

12. Gilley DW, Wilson RS, Beckett LA, Evans DA. Psychotic symptoms and physically aggressive behavior in Alzheimer's disease. J Am Geriatr Soc 1997 Sep; 45(9):1074-1079. [PubMed]

13. Gormley N, Rizwan M R. Prevalence and clinical correlates of psychotic symptoms in Alzheimer's disease. Int J Geriatr Psychiatry 1998 Jun; 13(6): 410-14. CrossRef] [PubMed] 
14. Holroyd S. Hallucinations and Dellusions in Dementia. Int Psychogeriatr 2000;12 /Suppl.1/: 113-117.

15. Jacoby R, Oppenheimer C, Dening T, Thomas A. Oxford Textbook of Old Age Psychiatry. Oxford University Press, 2008:428

16. Janzing JGE, Naarding P, Eling P. Depressive Symptoms Predict Slow Cognitive Decline in Mild Dementia. Dement Geriatr Cogn Disord. 2005; 20(23):77-81. Epub 2005 May 20. [CrossRef] [PubMed].

17. Jeste DV, Finkel SI. Psychosis of Alzheimer's disease and related dementia. Am J Geriatr Psychiatry 2000; 8(1):29-34. [PubMed]

18. Levy ML, Cummings JL, Fairbanks LA, Bravi D, Calvani M, Carta A. Longitudinal assessment of symptoms of depression, agitation and psychosis in 181 patients with Alzheimer's disease. Am J Psychiatry 1996 Nov; 153(11):1438-43. [PubMed]

19. Lyketsos CG, Steinberg M, Tschanz JT, Norton MC, Steffens DC, Breitner JC. Mental and behavioral disturbances in dementia: findings from the Cache County Study on Memory in Aging. Am J Psychiatr 2000 May; 157(5):708-14. [PubMed]

20. Mega MS, Cummings JL, Fiorello $\mathrm{T}$, Gornbein J. The spectrum of behavioral changes in Alzheimer's disease. Neurology 1996; 46:130-5.

21. Mendez MF, Martin RJ, Smyth KA, Whitehouse PJ. Psychiatric symptoms associated with Alzheimer's disease. J Neuropsychiatry Clin Neurosci 1990 Winter; 2(1):28-33. [PubMed]
22. Morris RK, Rovner BW, Folstein MF, German PS. Delusions in newly admitted residents of nursing homes. Am J Psychiatry 1990; 147:299-302.

23. Roberts VJ, Ingram SM, Lamar M. Prosody impairment and associated affective and behavioral disturbances in Alzheimer's disease. Neurology 1996; 47:1482-88.

24. Rubin EH, Drevets WC, Burke WJ. The nature of psychotic symptoms in senile dementia of the Alzheimer type. J Geriatr Psychiatry Neurol 1988 Jan;1(1):16-20. [PubMed]

25. Wragg RE, Jeste DV. Overview of depression and psychosis in Alzheimer's disease. Am J Psychiatry 1989 May; 146(5): 577-578. [PubMed]
Address for correspondence:

Mariana Arnaoudova-Jekova, MD, PhD

Third Psychiatric Clinic MHAT "St. Marina"

1, Hristo Smirnenski str, 9010 Varna, Bulgaria;

Mobile: +359888512627

e-mail: marnaudova@hotmail.com 